
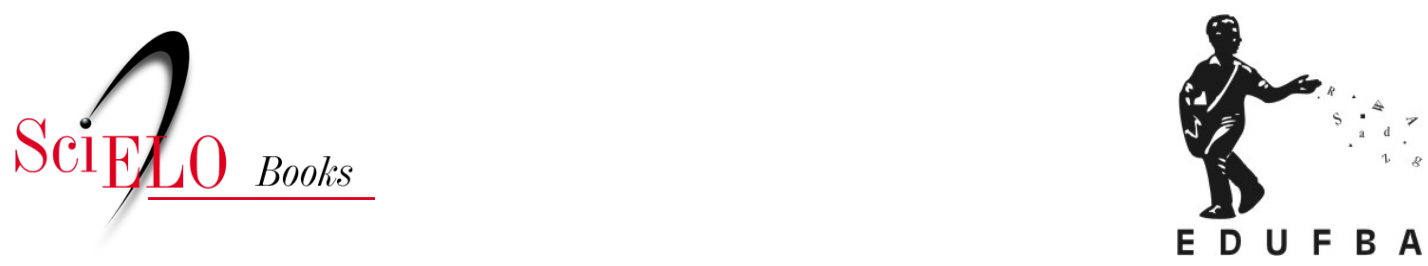

\title{
Parte 1 - Do CachoeiraDoc \\ Percursos e convergências: caminhos de aproximação entre a jornada de cinema da Bahia e o CachoeiraDoc
}

Izabel de Fátima Cruz Melo

\section{SciELO Books / SciELO Livros / SciELO Libros}

MELO, I. F. C. Percursos e convergências: caminhos de aproximação entre a jornada de cinema da Bahia e o CachoeiraDoc. In: CESAR, A., MARQUES, A. R., PIMENTA, F., COSTA, L., eds. Desaguar em cinema: documentário, memória e ação com o CachoeiraDoc [online]. Salvador: EDUFBA, 2020, pp. 83-97. ISBN: 978-65-5630-192-1. https://doi.org/10.7476/9786556301921.0005.

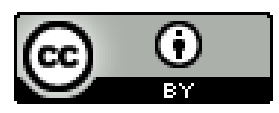

All the contents of this work, except where otherwise noted, is licensed under a Creative Commons Attribution 4.0 International license.

Todo o conteúdo deste trabalho, exceto quando houver ressalva, é publicado sob a licença Creative Commons Atribição 4.0.

Todo el contenido de esta obra, excepto donde se indique lo contrario, está bajo licencia de la licencia Creative Commons Reconocimento 4.0. 


\title{
Percursos e convergências: caminhos de aproximação entre a jornada de cinema da Bahia e o CachoeiraDoc
}

\author{
Izabel de Fátima Cruz Melo
}

\section{O lugar dos festivais na história do cinema}

Em que pese a sua importância para o campo cinematográfico, os festivais de cinema são objetos recentes na história e historiografia do cinema. Segundo Aida Vallejo (2015), o crescimento na quantidade de festivais e o aumento da sua influência na circulação e produção cinematográfica a partir da década de 1990 serviram como um indício que despertou a atenção dos pesquisadores na década seguinte, abrindo então um novo flanco nos marcos teóricos e metodológicos no que tange às investigações. Isso criou espaço para que as publicações relativas aos festivais ultrapassassem os marcos celebrativos e pudessem também se constituir em pontos de reflexão sistemática a respeito do lugar e significado que esses eventos ocupam na organização do próprio campo, através da sua variedade que se manifesta no porte, tema e objetivos, dentre outras características que implicam a necessidade de uma abordagem multidisciplinar, para que o festival, como objeto de pesquisa, possa ser delineado de forma mais precisa.

Nessa perspectiva, o trabalho de Marijke de Valck (2007) é considerado como um dos marcos significativos dessa sistematização, por organizar, ainda que sob um ponto de vista eurocentrado, um modelo analítico que, através de uma perspectiva histórica, busca compreender em quais contextos e circunstâncias os primeiros festivais foram criados. Além disso, percebe suas transformações internas, e também historiográficas, ao inseri-los ou reconhecê-los como parte dos objetos da nova história do cinema, chamando atenção para a necessidade de reflexões específicas que deem conta da multiplicidade dos formatos que estão abrigados sob o mesmo nome. 
Friccionando o apontamento relativo às já citadas reflexões específicas, trataremos brevemente da trajetória da Jornada de Cinema da Bahia e do CachoeiraDoc, festivais realizados na Bahia, em períodos diferentes, mas com pontos de convergência que permitem um esboço de abordagem comparatista, pois, como sublinha Mariana Souto (2018, p. 9),

A comparação tem uma relação parceira com a teorização. Da reflexão conjunta sobre algumas obras advém a possibilidade de depreender conceitos teóricos importantes. A perspectiva comparatista, com suas ambições mais abarcadoras, pode ser vista como laboratório de experimentação da teoria. Por outro lado, de sua prática derivam-se panoramas, compreensões globais, conceitos. A comparação, ao lidar com um certo alargamento em relação ao trabalho com um único objeto, parece facilitar a transposição de raciocínios e propiciar uma espécie de trampolim para o pensamento.

Embora no seu texto a autora se refira diretamente à análise fílmica, penso que essa abordagem pode servir como uma poderosa reflexão a respeito dos caminhos possíveis para pesquisas também na história do cinema, espaço no qual nos situamos e a partir do qual enxergamos e buscamos compreender os festivais.

Na nossa perspectiva, eles se constituíram como espaços fundamentais para a comunidade cinematográfica, pois através deles há uma intensa circulação não só dos filmes, pois junto com eles e suas equipes a presença dos críticos, público interessado e imprensa cria uma ambiência fértil, em que transitam pessoas, planos, práticas e ideias que podem ser consideradas de extrema importância para quem ali está. Isso vale para os realizadores e para todos os profissionais envolvidos com os diversos aspectos da vivência cinematográfica, pois é um espaço propício para novas ou aprofundamento de parcerias e colaborações.

Para o público, torna-se um lugar oportuno no qual é possível ter contato tanto com as produções contemporâneas quanto com as tidas como históricas, de períodos ou nacionalidades diversas, que dificilmente encontram espaço e visibilidade nas salas de cinema ou ainda em outras janelas do audiovisual. De forma geral, o que nos chama atenção é que todos esses processos ainda contemporaneamente se articulam de forma ampla com a ideia de formação, ${ }^{1}$ mesmo com

1 Aproximamo-nos aqui da proposta de Raymond Williams para pensar a ideia de formação, como uma análise de uma prática especializada que se torna mais visível ao tratarmos de movimentos literários, 
o crescimento significativo do número de cursos de graduação em cinema e/ou audiovisual. Dessa forma, o nosso prisma ao nos aproximar tanto da Jornada, quanto do CachoeiraDoc, tende a essa direção.

\section{(Re)apresentando a Jornada de Cinema da Bahia dos anos 1970}

A Jornada de Cinema da Bahia pode ser considerada como um dos mais longevos festivais de cinema do Brasil, tendo a sua primeira edição em 1972 e a última em 2012. Durante esse período, sua nomenclatura oficial variou, passando por Jornada Baiana de Curta-Metragem (1972), Jornada Baiana de CurtaMetragem (1973), Jornada Brasileira de Curta-Metragem (1974) e por fim Jornada Internacional de Cinema da Bahia (1985). Nessas mudanças, é possível notar as transformações e ambições do evento no transcurso do tempo. Contudo, todas as denominações foram resumidas a “Jornada de Cinema da Bahia”, denominação consolidada na memória e história do cinema no Brasil. A Jornada é criada como uma das atividades do Grupo Experimental de Cinema (GEC), atividade extensionista da Universidade Federal da Bahia (UFBA), sediada inicialmente em Salvador, assim como o Curso Livre de Cinema, em 1968, e a Mostra do Filme Etnográfico, em 1973, e dentre as três foi a única que, apesar dos percalços, conseguiu autonomia de tal forma que sobreviveu mesmo após o declínio do GEC.

Uma das suas principais características se explicita na resistência que seu organizador, Guido Araújo, ${ }^{2}$ tinha a respeito do termo "festival”, considerado por ele como um tipo de evento celebrativo e pouco comprometido com os principais problemas do cinema brasileiro de então (anos 1970). Araújo buscava posicionar

artísticos ou científicos, mas que não são passíveis de serem a resumidos a relações meramente institucionais, pois a complexidade das relações culturais torna esse fenômeno muito mais fluido e simultaneamente resistente "a uma função hegemônica generalizada". Cf. Williams (1979, p. 122).

2 Guido Antônio Sampaio de Araújo (1933-2017) nasceu em Castro Alves. Mudou-se para Salvador durante os anos 1940 e, aos 19 anos, vai para o Rio de Janeiro, trabalhando como assistente de direção de Nelson Pereira dos Santos. No início dos anos 1960 viajou para Tchoslováquia, onde continua seus estudos em cinema, retornando ao Brasil em 1967. Em 1968 junto com Walter da Silveira fundou o GEC e, em 1972, a Jornada de Cinema da Bahia. Depois do falecimento de Walter da Silveira em 1970 além de continuar com o GEC, tornou-se coordenador e programador do Clube de Cinema da Bahia (CCB), além de dirigir documentários sobre diversos aspectos da vida cultural baiana e, posteriormente, professor emérito do curso de Comunicação da UFBA. Araújo foi um dos principais mediadores do campo cinematográfico na Bahia. 
a Jornada numa perspectiva de um ambiente de trabalho, inicialmente voltado para a exibição de curtas-metragens e em defesa dos interesses dos documentaristas brasileiros, tanto do ponto de vista das políticas públicas, quanto do que se desejava como mercado para o filme brasileiro (MELO, 2018).

Dialogando com a categorização de de Valck (2007) e Tetê Mattos (2013), podemos localizar a Jornada como um dos festivais que se inicia na "era dos programadores" e que tem como forte característica também a centralidade dos temas políticos, não apenas nos filmes, mas em sua programação de forma geral, estabelecendo-se durante a ditadura militar como um dos espaços de resistência cultural, funcionando como um ambiente considerado seguro. Assim,

É importante marcar que guardando as singularidades de cada um dos eixos aqui escolhidos, o CCB, o GEC e a Jornada têm aproximações que se estabelecem especialmente a partir da já citada marca curatorial de Guido Araújo que imprime nas atividades um interesse formativo que ultrapassou a cinefilia e firmou um posicionamento que se preocupava, afinado com as questões do período, em encontrar saídas para as dificuldades encontradas pelo cinema brasileiro na ocupação do mercado, e simultaneamente profundamente inserido nos debates políticos vividos pelo Brasil da época. (MELO, 2018, p. 113)

Nessa perspectiva, a Jornada abrigava as mostras competitivas, que aceitavam filmes em super-8, $16 \mathrm{~mm}$ e $35 \mathrm{~mm}$, e, mesmo voltada inicialmente para o documentário, abriu espaço para animação e os experimentais. Além das competitivas, havia também os seminários, simpósios, mostras informativas e paralelas, bem como debates. Toda essa programação, que durava de 7 a 10 dias, era possível devido à construção de redes de cooperação, ativadas por Guido Araújo, no primeiro momento com a UFBA e na sequência com embaixadas, consulados, cinematecas, outros festivais e associações culturais, especialmente o Goethe Institut. Nessas articulações, ampliaram-se as redes de parcerias, ao mesmo tempo que assistimos à fundação e reestruturação de instituições vinculadas ao campo cinematográfico, tais como a Associação Brasileira de Documentaristas (ABD), as federações nacional e regionais do movimento cineclubista, o Encontro dos Pesquisadores do Cinema Brasileiro, o mercado paralelo e os debates sobre a Dinafilme. (MELO, 2016) 
Além disso, os simpósios e seminários ocorridos durante a Jornada estavam diretamente relacionados com os temas e problemas enfrentados pelo campo cinematográfico brasileiro e latino-americano, tais como o lugar do curta-metragem no mercado cinematográfico, o papel do cinema no que tange às questões políticas e identitárias, as relações entre o campo e os órgãos governamentais, tanto no sentido do estímulo à produção, distribuição e formação, quanto em relação aos entraves causados pela censura. Apenas à guisa de ilustração, houve em 1973 o Simpósio sobre o mercado do filme de curta-metragem, composto das seguintes falas: "Uma atitude cultural para o Super-8”, por Jean-Claude Bernardet; "O curta-metragem como instrumento de pesquisa”, por Alex Viany; "As opções do curta-metragem no panorama cultural”, por José Carlos Avelar; "Legislação brasileira sobre curta-metragem”, por Thomas Farkas; "Características do mercado paralelo para o filme de curta-metragem”, por Aluísio Leite Filho; “A atuação dos cineclubes na divulgação do curta-metragem”, por Marco Aurélio Marcondes; e "Uma experiência: o cinema de arte de Recife”, por Celso Marconi. (TAVARES, 1978, p. 16)

No tocante às mostras paralelas e informativas realizadas nas edições das Jornadas, observamos quais as relações que o evento estabelece, a partir da curadoria organizada por Guido Araújo, com outros festivais, filmografias e temas que nem sempre estão presentes nos filmes concorrentes nos certames. Na nossa perspectiva, essas mostras funcionam também como um elemento formativo, ao proporcionar aos participantes da Jornada, seja os cineastas, seja o público em geral, uma aproximação mais abrangente tanto de filmes contemporâneos realizados em outros países, quanto de uma produção brasileira pouco vista.

Também como exemplo houve, em 1973, a Mostra Oberhausen, a Retrospectiva Thomas Farkas e a Mostra Informativa Nacional Super-8; em 1974 a Mostra Informativa de Cinema Documental, a Retrospectiva do Cinema Primitivo Nordestino e a Mostra Informativa de Cinema Documental; em 1976 a Mostra Hors-Concours, a Mostra Bilbao na Bahia I e II e, por fim, a Mostra Informativa do Filme Latino-Americano I e II; e em 1978 a Mostra comemorativa 20 anos da Cinemateca do MAM, a Homenagem a Olney São Paulo; a Mostra do Filme Infanto-Juvenil, a Informativa do Filme Curto Latino-Americano, a Retrospectiva dos Filmes Destacados das Jornadas passadas, o Programa do Centro de Pesquisadores do Cinema Brasileiro e a Mostra Especial do Filme Documentário. (VII JORNADA..., 1978) Assim, depois dessa breve apresentação 
da Jornada e sua programação, vamos nos tratar do CachoeiraDoc, pensando também sua organização a partir da mesma ideia de formação.

\section{Cachoeira.Doc: uma aproximação}

O Festival de Documentários de Cachoeira, CachoeiraDoc, cuja primeira edição aconteceu em 2010, é uma iniciativa de Amaranta César, coordenada em parceria com Ana Rosa Marques, ambas professoras do curso de Cinema da Universidade Federal do Recôncavo da Bahia (UFRB). Diferentemente da Jornada, o CachoeiraDoc é parte de um contexto de expansão das políticas públicas de educação e cultura, tanto no âmbito estadual, quanto no federal, que através da universidade pública e dos editais de fomento possibilitaram a realização de um festival, no interior do estado da Bahia, que se propõe a "contribuir para a renovação da tradição documental”. (CACHOEIRADOC..., 2010)

O CachoeiraDoc escapa às classificações propostas por Vallejo (2016), de Valck (2007) e Mattos (2013), ou as hibridiza de maneira mais intensa, ao permanecer com uma forte marca curatorial, que para as duas primeiras faz parte da já citada “era dos programadores”. Esta, na perspectiva de Vallejo (2016) e de Valck (2007), entrou em declínio nos anos 1980, mantendo como duas linhas mestras tanto as dimensões estéticas, quanto as políticas, na organização da programação, como explicitam os textos de apresentação do festival e das mostras nos catálogos das oito edições até então realizadas. Isso indica a ambição de constituir um diálogo com as questões do contemporâneo, trazendo para o espaço do CachoeiraDoc temas e tensões que potencializam mais uma vez a compreensão dos festivais como lugares de encontro, trocas e formação.

Uma das principais características do festival, a qual se vincula fortemente ao viés da formação, é a participação dos estudantes de graduação na produção e na curadoria, ministrando oficinas e selecionando filmes para a programação, bem como no júri jovem, que de forma independente do júri oficial premia os melhores filmes das mostras competitivas. Acompanhando a ficha técnica e os catálogos de cada edição, é possível mapear a circulação dessas pessoas e observar como a relação do festival com a universidade ocorre não apensas na dimensão estrutural - no sentido de ceder espaço para as exibições, debates, transporte, entre outras coisas -, mas sobretudo, em nossa perspectiva, proporcionando 
um espaço de experimentação vinculada às aprendizagens, tensões e fricções do campo cinematográfico de maneira mais ampla.

De forma geral, o CachoeiraDoc é formado pelas mostras competitivas de curta e longa-metragem, mostras especiais, mostras paralelas, oficinas, sessões especiais e conferências. No decorrer dos anos, apesar da alteração da conjuntura e contexto social e político brasileiro, com o golpe de 2016 e questões antecedentes, o evento cresceu e reafirmou o seu interesse por uma agenda progressista, marcadamente vinculada aos debates de raça, gênero, sexualidade e seus desdobramentos. Estes são entendidos no sentido tanto das suas potencialidades, quanto das tensões com a política e estética do próprio campo cinematográfico, bem como do mundo social de forma mais ampliada. Isso leva o cinema, especialmente no caso do documentário, foco do festival, a ser considerado um espaço de intervenção e reelaboração das imagens, representação e autoria, a partir desses recortes.

Nessa perspectiva, ao observarmos mais detidamente a programação, as escolhas curatoriais materializam essas linhas, perceptíveis na força do cinema indígena, negro e de mulheres e LGBTQ+. Em suas produções, extrapolando e questionando uma certa tradição do documentário brasileiro, esses sujeitos ultrapassam o lugar de temas e passam a ser elaboradores sofisticados das suas próprias imagens e narrativas. Essa mudança faz com que não só nos debates, mas também na programação, os “clássicos do real” possam ser exibidos, questionados e postos em perspectiva, numa homenagem que, menos interessada em reafirmar os seus lugares na história do cinema documentário, interpele o presente e proponha novas formas de leitura e aproximação. Dentre esses clássicos, estiveram Geraldo Sarno, em 2010, Alexandre Robatto, em 2013, Guido Araújo, em 2015, e Luís Paulino dos Santos, em 2017. Cineastas de atuação variada, mas que têm em comum na sua produção o interesse pelas culturas populares, do recôncavo, sertão ou litoral baiano e nordestino.

No que diz respeito às mostras especiais, em 2010 houve as mostras "Cinema sem fronteiras", "Paralela Bahia” e "Paralela Recôncavo"; em 2011 "Agnès Varda" e "Documentários experimentais"; em 2012 "Caros diários” e "25 anos do Vídeo nas Aldeias"; em 2013 "Áfricas: filmes de regresso e questões à terra natal”, "Recôncavo" e "Cinema na real”. Já em 2014, houve as mostras "Jia Zhangke”, "Kékó" e "Resistência”; em 2015 "Perspectivas do espaço e imersões sensoriais", "Soy Cine" e o retorno do "Cinema na real”. Em 2016, o espaço das mostras 
especiais é ocupado pela Mostra Contemporânea, com as sessões "Gênero - a pele que vestimos”, "Espaços em disputa”, "O fim e o (re)começo do mundo”, "Bahia: ruínas em construção”, e pela mostra Cinema com Mulheres, organizada em curadoria coletiva por Yasmin Thayná, Lis Kogan, Carla Maia, Janaína Oliveira, Ana Carvalho, Marisa Cardozo, Mariana Porto e Marisa Merlo. Por fim, em 2017, as mostras especiais foram "Corpos em luta”, "Memórias em luta” e "Cinema de lutas”, com curadoria compartilhada por Amaranta César, Nicole Breneze Victor Guimarães.

As conferências e mesas-redondas têm um espaço privilegiado na programação do festival. Elas deslizam entre temas relacionadas aos aspectos mais técnicos e formais relativos à produção documental - como as sobre "Cinema e educação", com Daiane Silva, Juliana de Carvalho e Ana Paula Nunes, e "Música e invenção no documentário”, com Guilherme Maia, Francisco Serafim e Ricardo Calil, em 2010; “Documentário, arte e técnica”, com Nicolas Hallet, Ute Fendler e Henriette Gunkel, e "Notas sobre Cinema Universitário”, com Rita Lima, Guilherme Sarmiento e os estudantes do PET Cinema UFRB, em 2011. Com o tempo vão se consolidando em torno de discussões que acompanham as demandas do próprio campo e dos filmes que compõem as mostras, sejam as competitivas ou as especiais e paralelas, colocando-se na intersecção da estética, história e política, como por exemplo, também em 2011, a conferência "Mídia indígena e o filme como 'autorretrato", com Joceny Pinheiro; a mesa-redonda "Resistir hoje", com Josias Pires e Ernesto Carvalho; as conferências sobre o cinema de Jia Zhangke, realizadas por Cecília Melo e Isaac Pipano, em 2014.

Em 2015, ocorreram as conferências "Cinema, universidade saberes tradicionais”, com César Guimarães; "Métodos e processos de formação: as oficinas nas periferias, comunidades tradicionais e territórios indígenas”, com Glaura Vale. Lara Belov (Coletivo Cinema e Sal) e Ernesto de Carvalho (Vídeo nas aldeias e Ocupe Estelita). Por fim, em 2017, o festival abriga em colaboração com o programa de pós-graduação em Comunicação (PPGCom) da UFRB o VI Colóquio Cinema, Estética e Política, organizado pelo Grupo Poéticas da Experiência, do PPGCom da Universidade Federal de Minas Gerais (UFMG), com a participação de lideranças negras e indígenas, além dos pesquisadores vinculados aos programas. (CACHOEIRADOC I..., 2010; CACHOEIRADOC II..., 2011; CACHOEIRADOC III..., 2012; CACHOEIRADOC VI..., 2013a; CACHOEIRADOC..., 2013b; CACHOEIRADOC V..., 2014; CACHOEIRADOC VII..., 2016; CACHOEIRADOC VIII... , 2017). 
Elencar as mostras, conferências e mesas-redondas, ainda que de forma parcial e não exaustiva, como fizemos aqui, nos auxilia a compreender os caminhos construídos pelo festival e sua organização, possibilitando visualizar as parcerias estabelecidas com outros festivais, e mostras, a partir dos seus curadores, trânsito dos filmes e perspectivas, bem como de outras universidades e pesquisadores. Estes, ao participarem da programação, tanto trazem suas contribuições e reflexões dos temas sobre os quais foram convidados a tratar, quanto certamente saem atravessados pelas questões que emergem da fricção com o real que o CachoeiraDoc provoca com a sua proposta de enfrentamento das questões envolvidas em inventar um festival de cinema no interior de um estado fora do dito eixo cinematográfico do Brasil. A partir dessa característica, podemos enfim explicitar as convergências que nos moveram a aproximar o CachoeiraDoc da Jornada de Cinema da Bahia.

\section{Convergências e continuidades no campo cinematográfico}

A Jornada e o CachoeiraDoc são exemplos de festivais que se propuseram a desviar a rota do circuito de exibição e debate sobre cinema no Brasil, explicitando e questionando, cada um à sua maneira, o entrave histórico do cinema brasileiro no que diz respeito à descentralização da produção, não só no sentido dos filmes, mas também do pensamento, escrita e reflexão. Em períodos diferentes, mobilizaram estratégias semelhantes para a realização desse intento: a partir de um suporte inicial construído com as universidades - a UFBA, no caso da Jornada, e a UFRB, no caso do CachoeiraDoc -, os seus organizadores estruturaram uma rede de articulação e solidariedade, mesclando apoios e presenças institucionais do Estado (seja o governo federal, estadual ou municipal), movimentos sociais, associações de classe, participação estudantil, outros festivais, consulados, associações culturais e relações pessoais para que as atividades ocorressem.

Há também em comum entre eles o estímulo ao caráter formativo do festival, o interesse pelo documentário e pelo cinema militante (ainda que essa categoria também se modifique no tempo, sentido e significados). Além disso, nota-se a permanência de alguns temas e sujeitos na programação (filmes, conferências e oficinas) dos dois festivais, tais como a já citada descentralização do cinema, 
as questões políticas e econômicas envolvidas com o fazer cinematográfico e, sobretudo, trabalhadores, periferias, violência do Estado, culturas populares, migração, imigração, cinemas latino-americano e africano. Estes são associados a pautas latentes nos anos 1970, mas já explicitamente presentes nos anos 2010, como os povos indígenas, negros, mulheres e população LGBTQ+, que como já citado anteriormente deixam de ser exclusivamente temas e se tornam realizadores e elaboradores das suas próprias imagens e narrativas, propondo cinemas negros, cinemas de mulheres, cinemas indígenas, cinemas LGBTQ+, cinemas periféricos, que tensionam, rasuram e questionam não só o cinema, mas também a sociedade brasileira. A existência desses novos realizadores e dessas novas imagens fala muito dos avanços, mas talvez ainda mais dos caminhos que nos faltam palmilhar na construção de uma vida em comum.

Por outro lado, chama nossa atenção como inesperadamente um paralelismo pode se aproximar por meio de cruzamentos. A Jornada começa em um momento de restrição e perseguição política e cultural, em 1972, durante a ditadura militar, existe e persiste durante toda a Nova República, até 2012, antes da inflexão, ou do "enigma” político de 2013, que, olhando hoje retrospectivamente, parece ter potencializado as forças que engendraram o golpe de 2016 e seus atuais desdobramentos. Por sua vez, o CachoeiraDoc se inicia em 2010, num momento, como também já foi dito, de expansão das políticas culturais e educacionais e aparente estabilidade, e agora atravessa um momento de uma nova escalada das restrições, perseguições e perdas de direitos que pareciam consolidados. Nessas flutuações que sublinham o quanto o cinema é inescapável à política, tanto a Jornada foi atingida nos anos 1990 pelo desmonte da Embrafilme e consequente desarticulação do campo cinematográfico no período, quanto o CachoeiraDoc em 2018, pela nova instabilidade que se abateu sobre o campo, nas esferas federal e estadual. Essa instabilidade, como de hábito, atinge mais fortemente os que não compõem o "eixo", os que se pretendem insurgentes e afeitos a questionamentos.

Como um breve parêntesis, devemos indicar que Cachoeira ${ }^{3}$ abrigou a produção dos filmes A montanha dos sete ecos (1963), de Armando de Miranda, Tenda dos milagres (1977), de Nelson Pereira dos Santos, Coronel Delmiro

3 Cachoeira é uma das cidades de expressão da cultura afro-baiana e um dos principais focos de resistência nas lutas pela consolidação da independência do Brasil na Bahia, em 1823, tanto por isso é também conhecida como Heroica e, uma vez por ano, transformada em capital do estado.

92 - Desaguar EM Cinema 
Gouveia (1978), de Geraldo Sarno, e O mágico e o delegado (1983), de Fernando Coni Campos. Além disso, o Clube de Cinema de Cachoeira recebeu em 1978 a VII Jornada Nordestina de Cineclubes, organizada pela Federação Nordestina de Cineclubes e coordenação do Clube de Cinema de Cachoeira (VII JORNADA..., 1978b, p. 6), além da existência de salas de cinema, aponta um histórico da cidade em relação as práticas cinematográficas.

Para além, ou talvez junto a tudo isso, assim como o CachoeiraDoc é sediado na cidade de Cachoeira, a Jornada, numa proposta de interiorização, em 1975 levou parte da programação à Feira de Santana e nos anos de 1983 e 1984 fez também de Cachoeira sua sede, para as XII e XIII Jornada Brasileira de CurtaMetragem (ARAÚJO, 2013). E mesmo reconhecendo a centralidadede de Robert Flaherty, não deixa de ser curioso que Nanook, o esquimó tenha sido escolhido pelos dois festivais para a sua abertura na mesma cidade, com 26 anos de intervalo entre as duas exibições. (XIII JORNADA..., 1984; I CACHOEIRADOC..., 2010) Somando-se a essa piscadela do passado para o presente, Guido Araújo, principal organizador da Jornada, documentarista, professor emérito da Faculdade de Comunicação da UFBA e no nosso entendimento um dos principais mediadores culturais do campo cinematográfico baiano e brasileiro, foi, como já dito anteriormente, um dos homenageados na mostra “Clássicos do Real”, pelo CachoeiraDoc.

Assim, nessa abordagem em que tentamos experimentar a possibilidade de comparação entre esses dois festivais realizados na Bahia, em períodos diferentes, mas com elementos que se revelaram próximos e que pelo menos provisoriamente nos permitem afirmar que o interesse e o engajamento do cinema nas questões contemporâneas, aliados ao reconhecimento do necessário diálogo com a história e a memória do cinema, podem ser reconhecidos como uma espécie de "herança" que a Jornada lega ao CachoeiraDoc, que à sua maneira segue com o cinema em busca "por um mundo mais humano."

\section{Referências}

ARAÚJO, Guido. As jornadas em Cachoeira. Cadernos de Cinema, [s. l.], 15 jun. 2013. Disponível em: https://bit.ly/3cEpZbj. Acesso em $10 \mathrm{dez}$ 2019. 
CACHOEIRADOC: 2015. Cachoeira: CachoeiraDoc, 2015. Programação do CachoeiraDoc: VI Festival de Documentários de Cachoeira.

Disponível em: http://cachoeiradoc.com.br/2015/. Acesso: 2 set. 2019.

Cachoeiradoc: I Festival de Documentários de Cachoeira. Cachoeira: [s. n.], 2010. Disponível em: https://issuu.com/leo.fcosta/docs/ cachoeiradoc. Acesso em 1 set. 2019.

CACHOEIRADOC: II Festival de Documentários de Cachoeira. Cachoeira: [s. n.], 2011. Disponível em: https://issuu.com/leo.fcosta/ docs/cachoeiradoc_catalogo. 1 set. 2019.

CACHOEIRADOC: III Festival de Documentários de Cachoeira. Cachoeira: [s. n.], 2012. Disponível em: https://issuu.com/leo.fcosta/ docs/catalogo. Acesso 3 set. 2019.

CACHOEIRADOC: IV Festival de Documentários de Cachoeira. Cachoeira: [s. n.], 2013a. Disponível em: https://issuu.com/leo.fcosta/ docs/cachoeiradoc4_catalogo. Acesso 1 set. 2019

CACHOEIRADOC: Relatório de edições anteriores. Cachoeira: [s. n.], 2013b. Disponível em: https://bit.ly/2G840xy. Acesso em: 10 nov. 2019. CACHOEIRADOC: V Festival de Documentários de Cachoeira. Cachoeira: [s. n.], 2014. Disponível em: http://www.cachoeiradoc.com. br/2014/. Acesso: 2 set. 2019.

CACHOEIRADOC: VII Festival de Documentários de Cachoeira. Cachoeira: [s. n.], 2016. Disponível em: https://issuu.com/leo.fcosta/ docs/cachoeiradoc7_cata_logo_web01. Acesso em 1 set 2019.

CACHOEIRADOC: VIII Festival de Documentários de Cachoeira. Cachoeira: [s. n.], 2017.

DE VALCK, Marijke. Film festivals: from European geopolitics to global cinephilia. Amsterdam: Amsterdam University Press, 2007.

MATTOS, Tetê. Festivais pra quê? Um estudo crítico sobre festivais audiovisuais brasileiros. In: BAMBA, Mahomed (org.). A recepção cinematográfica: teoria e estudos de casos. Salvador: Edufba, 2013. p. 117-130.

MELO, Izabel de Fátima Cruz Melo. Cinema, circuitos culturaise espaços formativos: novas sociabilidades e ambiência na Bahia. 2018. Tese (Doutorado em Meios e Processos Audiovisuais) - Universidade de São Paulo, São Paulo, 2018. 
MELO, Izabel de Fátima Cruz. "Cinema é mais que filme”: uma história das Jornadas de Cinema da Bahia. Salvador: Eduneb, 2016.

SOUTO, Mariana. Por um cinema comparado: possibilidades metodológicas da pesquisa em audiovisual. [S. l.: s. n.], 2018. Projeto de pós-doutorado apresentado ao programa de pós-graduação em Meios e Processos Audiovisuais da Escola de Comunicação e Artes da Universidade de São Paulo. Disponível em: https://bit.ly/34BaQ81. Acesso 10 dez. 2019.

TAVARES, Bráulio. O curta metragem brasileiro e as Jornadas de Salvador. Salvador: Gráfica do Banco Econômico, 1978.

VALLEJO, Aida. Festivales cinematográficos: em el punto de mira de la historiografía fílmica. Secuencias, Madrid, n. 39, ago. 2016. Disponível em: https://revistas.uam.es/secuencias/article/view/5838. Acesso em: 24 dez. 2019.

VII JORNADA Brasileira de Curta Metragem: Paulo Emílio Sales Gomes. Salvador: [s. n.], 1978a. Programa de evento ocorrido de 8 a 15 de setembro de 1978.

VII JORNADA Brasileira de Curta Metragem: Paulo Emílio Sales Gomes. Salvador: [s. n.], 1978b. Regulamento de evento ocorrido de 8 a 15 de setembro de 1978a.

VII JORNADA de Cineclubes Nordestina. A Tarde, Salvador, p. 6, 29 jul. 1978b.

WILLIAMS, Raymond. Marxismo e literatura. Rio de Janeiro: Zahar, 1979.

XIII JORNADA Brasileira de Curta-Metragem. Cachoeira: [s. n.], p. 6, 1984. Programa de evento ocorrido de 8 a 14 de setembro de 1984. 